\title{
Correlation, Path and Regression Analysis in Some Bread Wheat (Triticum aestivum L) Genotypes under Normal Irrigation and Drought Conditions
}

\author{
H.M. Fouad
}

Department of Agronomy, Faculty of Agriculture, Minia University, Minia, Egypt.

\begin{abstract}
T HE OBJECTIVE of this study was to assess correlation, path and regression analysis in 39 F6 bread wheat (Triticum aestivum L) genotypes during two seasons, i.e., 2015/2016 (F7) and 2016/2017 (F8) under irrigation and drought stress conditions at Fac. Agric. Edu. Farm, Minia University, Egypt. A positive correlation was found between grain yield and each of the number of spikes/plant and number of grains/spike under the two conditions. Path analysis revealed high positive direct effects on grain yield/plant via the number of grains/spike (0.929) under irrigation and number of spikes/plant (0.973) under drought. The direct effect of 100 -grain weight on grain yield/plant was positive under irrigation (0.649) and drought $(0.260)$. The indirect effects of these traits were negative under the two conditions. Stepwise regression analysis revealed that three models no. 8,9 and 10 were fitted for each environment. The model no. 8 included one trait; the number of grains/spike under irrigation and number of spikes/plant under drought. Its relative contributions in grain yield were 0.180 and 0.693 under irrigation and drought; respectively. The model no. 9 in the two environments included two traits; the number of grains/spike and number of spikes/plant, its relative contributions in grain yield/plant were 0.544 and 0.836 under normal and drought conditions, respectively. The model no. 10 included three traits number of grains/spike, number of spikes/plant and 100-grain weight, its relative contribution in grain yield/plant were 0.0.931 and 0.978 under normal and drought conditions, respectively. This model no. 10 is fit and superior to use in selection for grain yield/plant.
\end{abstract}

Keywords: Bread wheat (Triticum aestivum L), Correlation, Path, Regression, Drought stress, Stepwise.

\section{Introduction}

Bread wheat (Triticum aestivum $\mathrm{L}$ ) is an important cereal crop not only all over the world, but also in Egypt. The grain yield in the wheat is a complex character that can be determined by several components, which reflect positive or negative effects upon this trait (Singh \& Chaudhary, 2006).

Grain yield is a quantitative trait and highly influenced by many genetic and environmental factors. Therefore, direct selection for grain yield is not effective in most cases and successful selection depends upon genetic variability and correlation between grain yield and morpho-physiological traits. Thus, Selection could be made for the yield components (Dixet \& Dubey, 1984).

Abd El-Mohsen \& Abd El-Shafi (2014) found highly significant differences among cultivars for all studied traits. Bhutto et al. (2016) revealed that significant differences among the genotypes for no. of spikes/plant, no. of grains/spike and grain yield/plant.

Correlations study is very important in plant breeding, because it reflects the dependence degree between two or more traits. If there is genetic correlation between two traits, direct selection of one trait can cause change in the other trait (Zecevic et al., 2004). Correlations between traits are depending of genetic and environmental factors. Environmental conditions can cause variability, not only in some traits but also interrelationships between them (Khan et al., 2005).

Khokhar et al (2010), Rasheed et al (2015), Khames et al (2016) and Jan et al (2017) observed positive phenotypic correlation for the grain yield with no. of tillers/plant and 1000-grain weight. Nasri et al (2014) showed significant positive 
correlation between the 1000-grain weight and no. of grains/spike. Bhutto et al (2016) observed highly positively phenotypic correlation between tillers/plant and grains/spike. Thus estimation of correlation and regression analysis among yield and yield components may provide effective selection criteria to improve wheat grain yield. Guler et al (2001) revealed that determining correlations among yield components traits was insufficient to selection in chickpea breeding. It was essential determine the direct and indirect effects of the causal components on the effect component.

Path analyses provide a measure of relative importance of each independent variable to predict changes in the dependent one. A path coefficient estimates the direct and indirect effects for one variable upon another and divides of correlation coefficient into direct and indirect effects. Consequently, correlation studies along with path analysis provide a better understanding of the association of different yield traits with grain yield (Dewey \& Lu, 1959) and (Dixet \& Dubey, 1984). Çifci (2012) and Desheva (2016) found that no. of grains/spike and no. of spikes/ plant had strongest direct effect on the grain yield/ plant. Abd El-Mohsen \& Abd El-Shafi (2014) and Rasheed et al (2015) revealed that the magnitude of positive direct effect on grain yield was through no. of grains/spike and 100-grain weight. Khokhar et al (2010) found that the highest positive indirect effect on yield was the no. of spikes/plant, indicating that the no. of spikes/plant may be an effective trait to select high yielded genotypes. Janmohammadi et al (2014) and Abd El-Mohsen \& Abd El-Shafi (2014) found that the 1000-grain weight had the most direct and positive effect on the grain yield.

Abd El-Mohsen \& Abd El-Shafi (2014) found that no. of grains/spike had the most direct and positive effect on grain yield (0.212). Khan et al (2013) showed that spikes $/ \mathrm{m}^{2}$, and the 1000 -grain weight had significant positive direct effects on the grain yield. However, the grains/spike had low direct positive effect but in low magnitude. Jan et al (2017) observed that the no. of grains/spike had negative (-0.15) direct effect with the grain yield. Khan \& Naqvi (2012) revealed that the no. of spikes and the no. of grains had direct positive effect on the grain yield under irrigated condition. Therefore, it is concluded that these traits could be selected for the different stress environments and it would be beneficial for the yield.
Stepwise regression is a method that is used to estimate the value of a quantitative variable regarding its relation with one or some other quantitative variables. This relation is such that it is possible to predict other changes using one variable. Many investigators have been used this technique on wheat such as Mohamed (1999) and Soleymanifard et al. (2012).

Nasriet al (2014) stated that stepwise regression was used to remove the effects of ineffective or low impact on yield traits in the regression model. Stepwise multiple linear regressions proved to be more efficient than the full model regression to determine the predictive equation for yield (Mohamed, 1999). Stepwise multiple linear regression aims to construct a regression equation that includes the traits accounting for the majority of the total yield variation. Spikes number and seed index were the most important variables contributing the total variability of the grain yield (Mohamed, 1999 and Abd El-Mohsen \& Abd ElShafi, 2014).

Abd El-Mohsen \& Abd El-Shafi (2014) revealed that based on simple regression analysis, linear regression of no. of tillers/plant, the no. of grains/spike, and the 1000-grain weight leads to increase the grain yield/plant by $0.67,0.30,0.64$ units, respectively. Also, stepwise multiple linear regression analysis revealed that four traits, i.e., the no. of tillers/plant, the no. of grains/spike, harvest index and the 1000-grain weight with $\mathrm{R}^{2}$ $=97.29 \%$, had justified the best prediction model.

The objectives of this study were to: 1- Study the correlation between yield and its components in bread wheat genotypes under normal and drought stress environment. 2- Assess the contributions of highest correlated traits with yield via path coefficient analysis under the two conditions. 3Determine the better models had the significance of the yield components affecting the grain yield via the simple, multiple and stepwise regression analyses.

\section{$\underline{\text { Materials and Methods }}$}

Thirty seven $\mathrm{F}_{6}$ genotypes derived from the cross Giza 168 x Sids 4 in addition to the two parents were grown in two separate experiments; normal irrigation (irrigated 6 times) and drought stress condition (irrigated only one time three weeks after planting irrigation) on November $20^{\text {th }}$ 
in the two successive seasons of $2015 / 2016\left(\mathrm{~F}_{7}-\right.$ generation) and 2016/2017 ( $\mathrm{F}_{8}$-generation) at the Fac. Agric. Edu. Farm, Minia University, Egypt. These materials were derived from the materials of Ph.D. study of the author. A randomized complete blocks design with three replications was used. The plot size was one row, $1.5 \mathrm{~m}$ in length, and $0.2 \mathrm{~m}$ in width. Seeds were sown by hand, $5 \mathrm{~cm}$ apart within a row. The recommended cultural practices for wheat production were adopted throughout the growing seasons. The pedigree of the parents is given in Table 1 .

\section{Studied traits}

In each season, data for the following studied traits were recorded as mean of ten guarded plants; the grain yield per plant (GY/P) in $g$, the number of spikes per plant (NS/P), the number of grains per spike $(\mathrm{NG} / \mathrm{S})$ and the 100 grain weight (100-GW) in $\mathrm{g}$.

\section{Statistical procedures}

Analysis of variance was performed on the studied traits as outlined by Steel \& Torrie (1980). The form of analysis of variance and expected mean squares are presented in Table 2.

The phenotypic $\left(\sigma^{2} \mathrm{p}\right)$ and genotypic $\left(\sigma^{2} \mathrm{~g}\right)$ variances were calculated according to the following formulas:

$$
\begin{gathered}
\sigma^{2} g=\left(M_{3}-M_{1}\right) / r . \\
\sigma^{2} p=\sigma^{2} g+\sigma^{2} e / r .
\end{gathered}
$$

Mean comparisons were calculated using Revised Least Significant Difference (RLSD) according to El Rawi \& Khalafalla (1980) as follows:

RLSD of Genotypes $=\mathfrak{t} . \sqrt{\frac{2 M s e}{r}}$ to compare among genotypes means.

where $r$ : Number of replicates and $t \backslash$ is the $t$ value from "minimum-average-risk t-table" at F-value of treatments, treatment d.f and experimental error d.f.

Phenotypic correlation coefficient was calculated as the procedure outlined by Johnson et al. (1955), as follows:

Phenotypic correlation $\mathrm{rp}_{\mathrm{xy}}=\operatorname{covp}_{\mathrm{xy}} /\left(\sigma \mathrm{p}_{\mathrm{x}} \cdot \sigma \mathrm{p}_{\mathrm{y}}\right)$.

Path coefficient analysis was done to divide the phenotypic correlation coefficients into direct and indirect effects. Path-analysis was done for grain yield/plant as dependent variable (effect) affected by three independent variables (causes), i.e., no. of spikes/plant, no. of grains/spike and 100 -grain weight. Path coefficient was estimated according to method of Deway \& Lu (1959).

Also, the regression analysis was done to determine the relationship between the causal, effect and significance the three independent yield components on grain yield. IBM SPSS Statistics program of ver. 21 was used to calculate simple, multiple, stepwise regression and coefficient of determination $\left(\mathrm{R}^{2}\right)$ in the two generations of both conditions.

TABLE1. The pedigree of the parents of the wheat genotypes.

\begin{tabular}{lc}
\hline Parental cultivars & \multicolumn{1}{c}{ Pedigree } \\
\hline Giza 168 & MIL/Buc//Seri CM93046-8M-04-0M-2Y-0B \\
Sids 4 & Maya (S)/Man (S)//CMH74A-592/3/Giza $157 * 2$ \\
\hline
\end{tabular}

TABLE 2. Form of combined analysis and expected mean squares.

\begin{tabular}{lccc}
\hline S.V & d.f. & M.S. & E.M.S. \\
\hline Years (y) & $\mathrm{y}-1$ & $\mathrm{M} 5$ & - \\
Reps x Years & $\mathrm{y}(\mathrm{r}-1)$ & $\mathrm{M} 4$ & - \\
Genotypes $(\mathrm{g})$ & $(\mathrm{g}-1)$ & $\mathrm{M} 3$ & $\sigma^{2} \mathrm{e}+\mathrm{ry} \sigma^{2} \mathrm{~g}$ \\
G x Y & $(\mathrm{g}-1)(\mathrm{y}-1)$ & $\mathrm{M} 2$ & $\sigma^{2} \mathrm{e}+\mathrm{r} \sigma^{2} \mathrm{~g} \mathrm{y}$ \\
Error & $\mathrm{ygr}-1$ & $\mathrm{M} 1$ & $\sigma^{2} \mathrm{e}$ \\
\hline
\end{tabular}

where: S.V: Source of variation; d.f.: Degree of freedom; M.S.: Mean squares and E.M.S.: Expected mean squares. $\mathrm{r}$ and $\mathrm{g}$ are number of replications and genotypes; respectively, $\sigma^{2} \mathrm{e}$ and $\sigma^{2} \mathrm{~g}$ are error and genetic variance; respectively. 


\section{Results and Discussion}

The combined analysis over the two years (Table 3) revealed that genotypes, years $\mathrm{x}$ genotypes interactions exhibited significant differences for all studied traits under the two environments Table 3. Many researchers found similar results such as Mahdy et al. (2015), and Bhutto et al (2016).

Means and reduction percentage of the studied traits for genotypes under normal and drought stress conditions averaged over the two seasons are presented in Table 4.

Average of the grain yield/plant, the no. of spikes/plant, the no. of grains/spike and the 100 -grain weight were 28.23 and 19.07 gm., 6.93 and 5.87, 77.58 and 70.39 and 5.44 and 4.73 under normal irrigation and drought stress conditions, respectively. Drought caused reduction in these four traits by $32.45,15.29,9.04$ and $13.08 \%$ respectively. (Mahdy et al 2015).

Phenotypic correlation coefficients among the studied traits under normal and drought stress conditions are presented in Table 5. Under normal irrigation, positive correlation was found between the grain yield/plant and each of the no. of spikes/ plant (0.332), the no. of grains/spike (0.425) and the 100 grain weight $(0.385)$. Under drought stress, phenotypic correlation was positive between the grain yield/plant and the no. of spikes/ plant (0.832). Correlation coefficients between the grain yield/plant and the 100 grain weight was changed from positive $(0.385)$ under the normal irrigation to negative correlation $(-0.211)$ under the drought stress. Negative phenotypic correlation coefficients were found among the no. of spikes/plant, the no. of grains/spike and the 100 grain weight under the two environments. Similar results were obtained by Janmohammadi et al. (2014), Abd El-Mohsen and Abd El-Shafi (2014), Rasheed et al. (2015), Khames et al. (2016), Desheva (2016) and Jan et al. (2017).

On the other hand, path analysis was used to divide the phenotypic correlation into direct and indirect effects. Therefore, the highest direct effect on the grain yield/plant was the no. of grains/ spike (0.929), followed by the no. of spikes/plant $(0.864)$ and the 100 grain weight $(0.649)$ under the normal irrigation. While, under the drought stress, the highest direct effect on the grain yield/ plant was the no. of spikes/plant (0.973) followed by the 100 grain weight $(0.260)$ and the no. of grains/spike (0.258) (Table 6). Similar results were obtained by Abd El-Mohsen and Abd ElShafi (2014) and Rasheed et al (2015).

The results of path coefficient analysis (Table 6 and Figure. 1) exhibited high positive direct effect of the number of spikes/plant on the grain yield under irrigation (0.864) and drought stress (0.973). These results were in agreement with Khan and Naqvi (2012). Moreover, its indirect effects were negative via other intervening traits such as the number of grains/spike and the 100 -grain weight $(-0.438$ and -0.041$)$ and $(-0.094$ and -0.100 ) under the normal irrigation and drought stress, respectively.

TABLE 3. Mean square for the studied traits of genotypes under normal irrigation and drought combined over the two years.

\begin{tabular}{lcccccc}
\hline Environ. & S.V & d.f & GY/P & NS/P & NG/S & $\mathbf{1 0 0 G W}$ \\
\hline \multirow{5}{*}{ Irrigation } & Years & 1 & $173.70^{* *}$ & 4.75 & $2383.51^{*}$ & 1.57 \\
& Reps x Years & 4 & 65.66 & 0.17 & 306.24 & 0.07 \\
& Genotypes & 38 & $79.60^{* *}$ & $3.97^{* *}$ & $668.44^{* *}$ & $1.60^{* *}$ \\
& G x Y & 38 & $43.25^{* *}$ & $1.99^{* *}$ & $278.83^{* *}$ & $0.52^{* *}$ \\
\multirow{3}{*}{ Drought } & Error & 152 & 5.07 & 0.10 & 24.77 & 0.38 \\
& Years & 1 & 112.58 & $4.77^{* *}$ & $7520.24^{* *}$ & 21.28 \\
& Reps x Years & 4 & 174.11 & 2.79 & 461.66 & 0.32 \\
& Genotypes & 38 & $56.23^{* *}$ & $8.02^{* *}$ & $418.28^{* *}$ & $0.67^{* *}$ \\
& G x Y & 38 & $13.02^{* *}$ & $0.68^{* *}$ & $142.18^{* *}$ & $0.67^{* *}$ \\
\hline
\end{tabular}

* and ** significant at 0.05 and 0.01 level of probability, respectively. 
TABLE 4. Means and reduction percentage in the studied traits for genotypes under normal and drought averaged over two seasons.

\begin{tabular}{|c|c|c|c|c|c|c|c|c|c|c|c|c|}
\hline \multirow{2}{*}{ Gen. No } & \multicolumn{3}{|c|}{ GY/P } & \multicolumn{3}{|c|}{$\mathbf{N S} / \mathbf{P}$} & \multicolumn{3}{|c|}{ NG/S } & \multicolumn{3}{|c|}{ 100GW } \\
\hline & $\mathbf{N}$ & D & $\%$ Red & $\mathbf{N}$ & D & $\%$ Red & $\mathbf{N}$ & D & \% Red & $\mathbf{N}$ & D & $\%$ Red \\
\hline 1 & 28.81 & 18.66 & 35.24 & 7.11 & 5.13 & 27.96 & 79.80 & 68.65 & 13.97 & 5.11 & 5.32 & -4.25 \\
\hline 13 & 28.93 & 19.24 & 33.52 & 6.15 & 5.65 & 8.18 & 102.03 & 72.65 & 28.80 & 5.03 & 4.77 & 5.20 \\
\hline 39 & 33.34 & 17.77 & 46.71 & 6.17 & 5.39 & 12.67 & 92.21 & 71.12 & 22.87 & 5.86 & 4.64 & 20.81 \\
\hline 42 & 30.79 & 14.44 & 53.11 & 6.27 & 5.08 & 18.94 & 84.57 & 56.28 & 33.45 & 5.93 & 5.09 & 14.19 \\
\hline 48 & 23.50 & 14.17 & 39.68 & 5.85 & 4.93 & 15.63 & 76.97 & 64.60 & 16.07 & 5.26 & 4.49 & 14.62 \\
\hline 62 & 29.01 & 20.72 & 28.58 & 7.38 & 6.66 & 9.75 & 76.10 & 61.96 & 18.59 & 5.26 & 5.01 & 4.72 \\
\hline 63 & 29.81 & 15.97 & 46.42 & 6.76 & 4.04 & 40.22 & 71.73 & 74.35 & -3.65 & 6.56 & 5.24 & 20.22 \\
\hline 68 & 35.53 & 18.99 & 46.56 & 7.16 & 4.73 & 33.95 & 82.38 & 81.08 & 1.58 & 6.19 & 4.92 & 20.51 \\
\hline 74 & 29.45 & 12.85 & 56.38 & 5.50 & 3.25 & 41.01 & 92.42 & 84.09 & 9.01 & 6.24 & 4.74 & 24.05 \\
\hline 92 & 31.16 & 16.02 & 48.57 & 6.27 & 4.12 & 34.25 & 105.62 & 97.19 & 7.99 & 5.06 & 4.01 & 20.71 \\
\hline 95 & 28.18 & 20.44 & 27.47 & 6.91 & 6.57 & 4.95 & 82.71 & 65.48 & 20.83 & 4.98 & 4.77 & 4.20 \\
\hline 104 & 30.96 & 18.95 & 38.80 & 6.94 & 6.62 & 4.56 & 96.72 & 69.06 & 28.60 & 4.60 & 4.21 & 8.35 \\
\hline 124 & 29.80 & 18.50 & 37.94 & 7.30 & 5.58 & 23.61 & 71.04 & 65.41 & 7.92 & 5.82 & 5.05 & 13.09 \\
\hline 129 & 27.36 & 16.28 & 40.49 & 6.80 & 4.97 & 26.83 & 74.71 & 66.12 & 11.51 & 5.43 & 4.94 & 8.95 \\
\hline 139 & 37.85 & 16.29 & 56.96 & 6.81 & 4.06 & 40.37 & 86.64 & 81.23 & 6.25 & 6.83 & 4.98 & 27.05 \\
\hline 145 & 25.33 & 19.96 & 21.22 & 6.28 & 5.68 & 9.51 & 79.83 & 75.25 & 5.74 & 5.09 & 4.68 & 8.00 \\
\hline 150 & 23.92 & 15.83 & 33.81 & 6.50 & 5.14 & 20.93 & 75.44 & 67.82 & 10.10 & 4.83 & 4.62 & 4.30 \\
\hline 151 & 25.48 & 20.36 & 20.07 & 7.98 & 7.23 & 9.31 & 58.46 & 58.36 & 0.18 & 5.61 & 4.82 & 13.97 \\
\hline 170 & 29.26 & 22.17 & 24.25 & 7.96 & 7.62 & 4.26 & 65.41 & 62.54 & 4.40 & 5.78 & 4.64 & 19.66 \\
\hline 202 & 30.54 & 21.58 & 29.34 & 7.01 & 6.18 & 11.77 & 78.79 & 71.11 & 9.74 & 5.59 & 4.90 & 12.29 \\
\hline 206 & 27.91 & 20.69 & 25.88 & 6.18 & 5.87 & 5.06 & 86.86 & 76.90 & 11.47 & 5.22 & 4.63 & 11.28 \\
\hline 209 & 27.78 & 18.46 & 33.55 & 7.05 & 5.69 & 19.32 & 75.75 & 72.88 & 3.78 & 5.26 & 4.50 & 14.42 \\
\hline 245 & 25.86 & 17.32 & 33.01 & 6.80 & 5.35 & 21.39 & 79.12 & 73.83 & 6.69 & 4.93 & 4.43 & 10.13 \\
\hline 246 & 24.94 & 17.38 & 30.30 & 7.72 & 7.06 & 8.60 & 66.71 & 57.06 & 14.48 & 4.99 & 4.31 & 13.69 \\
\hline 296 & 25.04 & 21.87 & 12.63 & 8.08 & 7.49 & 7.34 & 72.64 & 76.26 & -4.98 & 4.35 & 3.96 & 9.07 \\
\hline 300 & 27.72 & 20.42 & 26.33 & 7.39 & 6.86 & 7.29 & 68.81 & 63.99 & 7.01 & 5.46 & 4.73 & 13.40 \\
\hline 306 & 27.88 & 23.99 & 13.93 & 6.93 & 6.82 & 1.57 & 71.97 & 69.17 & 3.90 & 5.61 & 5.13 & 8.62 \\
\hline 343 & 27.21 & 18.67 & 31.39 & 7.61 & 6.08 & 20.00 & 70.04 & 62.99 & 10.07 & 5.21 & 4.93 & 5.28 \\
\hline 352 & 26.96 & 17.45 & 35.29 & 7.73 & 6.07 & 21.50 & 60.64 & 63.38 & -4.52 & 6.08 & 4.60 & 24.25 \\
\hline 378 & 31.95 & 24.91 & 22.04 & 7.52 & 7.27 & 3.29 & 83.57 & 74.01 & 11.44 & 5.11 & 4.70 & 8.16 \\
\hline 379 & 30.07 & 25.30 & 15.84 & 8.19 & 7.38 & 9.87 & 74.81 & 83.48 & -11.59 & 4.95 & 4.14 & 16.31 \\
\hline 389 & 27.22 & 20.13 & 26.03 & 6.95 & 5.60 & 19.44 & 67.78 & 68.59 & -1.19 & 5.98 & 5.23 & 12.41 \\
\hline 395 & 28.31 & 24.02 & 15.16 & 6.76 & 7.40 & -9.44 & 80.44 & 75.28 & 6.41 & 5.23 & 4.33 & 17.17 \\
\hline 397 & 31.21 & 23.32 & 25.28 & 7.97 & 7.60 & 4.57 & 74.00 & 69.61 & 5.94 & 5.35 & 4.51 & 15.64 \\
\hline 423 & 25.53 & 19.29 & 24.45 & 7.30 & 6.28 & 13.94 & 65.16 & 65.45 & -0.46 & 5.56 & 4.69 & 15.70 \\
\hline 459 & 21.41 & 17.51 & 18.22 & 5.71 & 5.83 & -2.12 & 67.15 & 63.96 & 4.75 & 5.52 & 4.77 & 13.49 \\
\hline 463 & 32.06 & 22.45 & 29.97 & 8.36 & 6.56 & 21.55 & 72.71 & 72.47 & 0.33 & 5.18 & 4.77 & 7.88 \\
\hline Sids4 & 18.23 & 14.51 & 20.42 & 4.53 & 3.47 & 23.37 & 79.26 & 80.11 & -1.08 & 5.29 & 5.25 & 0.71 \\
\hline Giza168 & 24.77 & 16.85 & 31.95 & 6.39 & 5.65 & 11.63 & 66.82 & 61.35 & 8.19 & 5.77 & 4.86 & 15.86 \\
\hline Average & 28.23 & 19.07 & 32.45 & 6.93 & 5.87 & 15.29 & 77.38 & 70.39 & 9.04 & 5.44 & 4.73 & 13.08 \\
\hline RLSD0.05 & 3.49 & 2.16 & - & 0.46 & 0.59 & - & 5.61 & 4.78 & - & 1.06 & 0.19 & - \\
\hline RLSD0.01 & 2.79 & 1.95 & - & 0.43 & 0.52 & - & 6.82 & 4.40 & - & 0.26 & 0.17 & - \\
\hline
\end{tabular}


TABLE 5. Phenotypic correlation coefficients among traits the under normal (below diagonal) and drought (above diagonal).

\begin{tabular}{lllll}
\hline Trait & GY/P & NS/P & NG/S & 100GW \\
\hline GY/P & & 0.832 & 0.008 & -0.211 \\
$\mathrm{NS} / \mathrm{P}$ & 0.332 & & -0.159 & -0.383 \\
$\mathrm{NG} / \mathrm{S}$ & 0.425 & -0.471 & & -0.368 \\
$100 \mathrm{GW}$ & 0.385 & -0.145 & -0.150 & \\
\hline
\end{tabular}

where: GY/P: Grain yield/plant, NS/P: Number of spikes/plant, NG/S: Number of grains/spike.

TABLE 6. Direct (diagonal) and indirect effects of the yield components on the grain yield under the normal irrigation and drought conditions.

\begin{tabular}{lcccccccc}
\hline \multirow{2}{*}{ Traits } & \multicolumn{4}{c}{ Irrigation } & \multicolumn{4}{c}{ Drought } \\
\cline { 2 - 9 } & NS/P & NG/S & $\mathbf{1 0 0 G W}$ & $\mathbf{r p}$ & NS/P & NG/S & 100GW & rp \\
\hline NS/P & $\mathbf{0 . 8 6 4}$ & -0.438 & -0.094 & 0.332 & $\mathbf{0 . 9 7 3}$ & -0.041 & -0.100 & 0.832 \\
NG/S & -0.407 & $\mathbf{0 . 9 2 9}$ & -0.097 & 0.425 & -0.154 & $\mathbf{0 . 2 5 8}$ & -0.096 & 0.008 \\
100GW & -0.129 & -0.139 & $\mathbf{0 . 6 4 9}$ & 0.385 & -0.372 & -0.099 & $\mathbf{0 . 2 6 0}$ & -0.211 \\
Residual effect & 0.263 & & & & 0.492 & & & \\
\hline
\end{tabular}

where: GY/P: Grain yield/plant, NS/P: Number of spikes/plant, NG/S: Number of grains/spike.

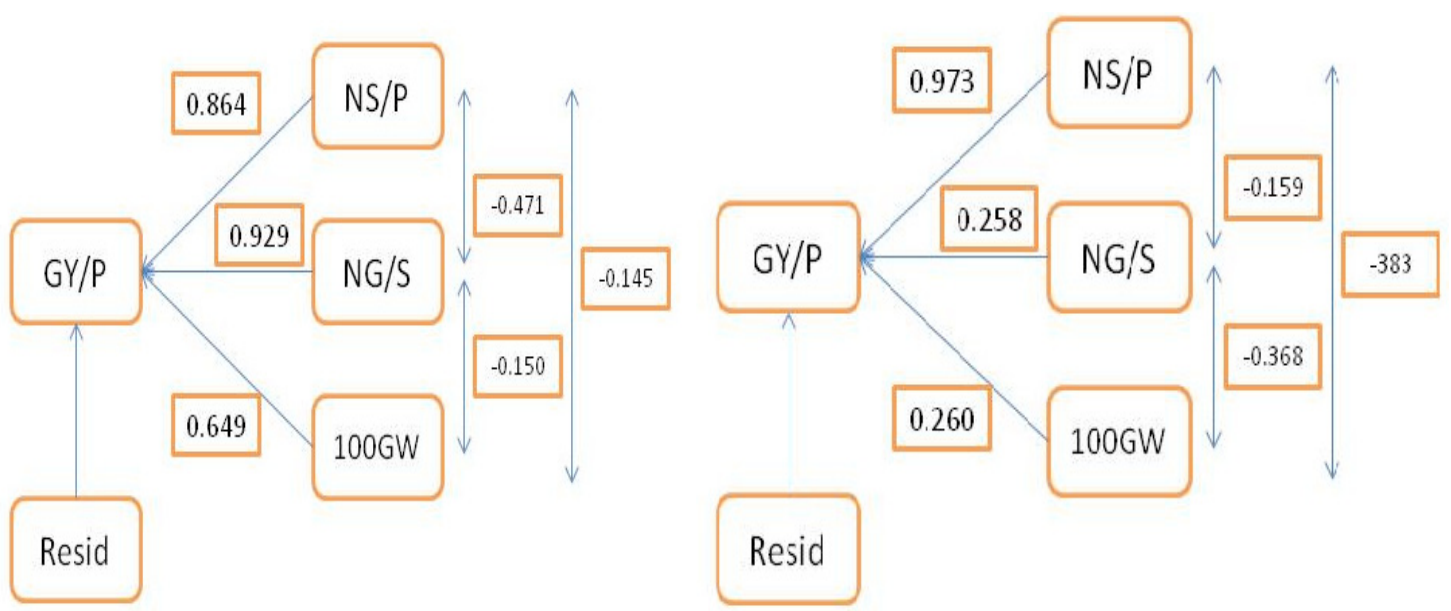

Fig. 1. Path coefficient diagram of the grain yield per plant indicating direct effects (single headed arrows) and correlation (double headed arrows) under normal irrigation (left) and drought stress (right). Where: GY/P: grain yield/plant, NS/P: Number of spikes/plant, NG/S: Number of grains/spike, 100GW: 100 grain weight and Resid: Residual effect.

Number of the grains/spike showed high positive direct effect (0.929) on the grain yield/ plant under irrigation and low direct effect (0.258) under the drought stress. Its indirect effects for the number of grains/spike on grain yield were negative via the number of spikes/plant and the 100-grain weight in both conditions. These results were in agreement with Çifci (2012) and Khan \& Naqvi (2012).

The direct effect of 100-grain weight on the grain yield per plant was positive under the 
irrigation (0.649) and the drought (0.260), its indirect effects characters were negative under the two conditions.

Simple, multiple and stepwise regression analyses are listed under irrigation (Table 7) and drought (Table 8). Results of the simple regression analyses revealed that the superior trait relative to other traits in its relative contributions in the grain yield/plant was the number of grains/spike (model no. 2) (0.180) under the normal irrigation and number of the spikes/plant (model no. 1) (0.693) the under drought stress. The 100-grain weight (model no. 3) was in the second order in the traits contributing in the grain yield/plant in the two environments. Similar results were reported by Abd El-Mohsen \& Abd El-Shafi (2014).

Multiple regression analyses revealed that under the normal irrigation (Table 7) the highest contribution in grain yield/plant was obtained via model no. 7 (0.931) followed by model no. 4 $(0.544)$. The two models included two traits, i.e., the number of spikes/plant and the number of grains/spike in addition to the 100-grain weight in model no. 7. Model no. 5 gave the lowest contribution in the grain yield/plant (0.302).

Under the drought stress, model no. 7 was the highest contribution in the grain yield by 0.978 followed by model no. 4 (0.836) then model no. 5 (0.707) (Table 8), where, these two models included two traits, i.e., the number of spikes/plant and the number of grains/spike in addition to the 100-grain weight in model no. 7. Model no. 6 gave the lowest contribution in the grain yield/plant (0.046).

Stepwise regression analysis revealed that the three models were fitted for each environment. The model no. 8 included one trait in both environments, i.e., number of the grains/ spike and its relative contribution in the grain yield was 0.180 under the normal irrigation and the number of spikes/plant and its relative contribution in the grain yield was 0.693 under drought condition. The model no. 9 in the two environments included two traits, i.e., number of the grains/spike and the number of spikes/plant and its relative contribution in the grain yield/ plant were 0.544 and 0.836 under the normal and the drought stress conditions, respectively. The model no. 10 included three traits $(\mathrm{NG} / \mathrm{S}$,
$\mathrm{NS} / \mathrm{P}$ and the 100-grain weight) and its relative contribution in the grain yield/plant were 0.931 and 0.978 under the normal and the drought stress conditions, respectively. This model no. 10 is fit and superior to use in selection for grain yield/plant. The stepwise regression used to remove the effects of ineffective or low the effective on the yield components in regression model. Moreover, the stepwise multiple linear regressions proved to be more efficient than the full model regression to determine the predictive equation for yield. These results are similar to reported by Abd El-Mohsen \& Abd El-Shafi (2014).

Values of $\chi^{2}$ between the realized and expected of the grain yield/plant were significant for all the studied models except model no. 7 out of multiple regression models and model no. 10 from models of stepwise regression under normal irrigation (Table 9). Moreover, the correlation coefficients between realized and expected grain yield were positive and highly significant for these models.

Under the drought stress, values of $\chi^{2}$ between the realized and expected the grain yield/plant were significant for model no. 1 from simple regression, models no. $4,5 \& 7$ out of multiple regression models and models no. $9 \& 10$ from models of the stepwise regression (Table 10). Moreover, the correlation coefficients between realized and expected the grain yield values were positive and highly significant for these models.

It could be concluded that model no. 7 equal to model no. 10 under both environments and included three traits, i.e., NS/P, NG/S and 100GW and model no. 4 equal to model no. 9 under drought stress included only two traits, i.e., $\mathrm{NS} / \mathrm{P}, \mathrm{NG} / \mathrm{S}$. Each of two models from these models possessed the same values of $\chi^{2}, \mathrm{R}$ and $\mathrm{R}^{2}$, indicating that variance of grain yield/ plant can be estimated by regression equations, where regression equation for model no.7 and 10 containing three traits, were $\hat{\mathrm{Y}}=-48.25+$ $0.320 \mathrm{NG} / \mathrm{P}+3.867 \mathrm{NS} / \mathrm{P}+4.57100-\mathrm{GW}$ under normal irrigation and $\hat{\mathrm{Y}}=-39.204+3.413 \mathrm{NS} / \mathrm{P}$ $+0.246 \mathrm{NG} / \mathrm{S}+4.423100-\mathrm{GW}$ under drought stress. Moreover, models no. 4 and 9 containing only two traits and its regression equation was $\hat{\mathrm{Y}}=-7.167+2.648 \mathrm{NS} / \mathrm{P}+0.152 \mathrm{NG} / \mathrm{S}$ under drought condition. 
TABLE 7. Simple, multiple and stepwise analysis in different models for grain yield/plant under irrigation.

\begin{tabular}{|c|c|c|c|c|}
\hline Reg type & $\begin{array}{l}\text { Model } \\
\text { No. }\end{array}$ & Independent trait/s & $\mathbf{R}^{2}$ & Regression equation \\
\hline \multirow{3}{*}{ Simple } & 1 & $\mathrm{NS} / \mathrm{P}$ & 0.110 & $\hat{\mathrm{Y}}=17.932+1.46 \mathrm{NS} / \mathrm{P}$ \\
\hline & 2 & $\mathrm{NG} / \mathrm{S}$ & 0.180 & $\hat{\mathrm{Y}}=16.892+0.1456 \mathrm{NG} / \mathrm{S}$ \\
\hline & 3 & 100GW & 0.148 & $\hat{\mathrm{Y}}=13.477+2.713100 \mathrm{GW}$ \\
\hline \multirow{4}{*}{ Multiple } & 4 & $\mathrm{NS} / \mathrm{P}, \mathrm{NG} / \mathrm{S}$ & 0.544 & $\hat{Y}=-12.930+3.062 \mathrm{NS} / \mathrm{P}+0.258 \mathrm{NG} / \mathrm{S}$ \\
\hline & 5 & NS/P, 100GW & 0.302 & $\hat{\mathrm{Y}}=-1.018+1.774 \mathrm{NS} / \mathrm{P}+3.119100 \mathrm{GW}$ \\
\hline & 6 & NG/S, 100GW & 0.386 & $\hat{\mathrm{Y}}=-2.523+0.170 \mathrm{NG} / \mathrm{S}+3.234100 \mathrm{GW}$ \\
\hline & 7 & $\mathrm{NS} / \mathrm{P}, \mathrm{NG} / \mathrm{S}, 100 \mathrm{GW}$ & 0.931 & $\begin{array}{l}\hat{Y}=-48.25+3.867 \mathrm{NS} / \mathrm{P}+0.320 \mathrm{NG} / \mathrm{S}+4.578 \\
100 \mathrm{GW}\end{array}$ \\
\hline \multirow{3}{*}{ Stepwise } & 8 & $\mathrm{NG} / \mathrm{S}$ & 0.180 & $\hat{\mathrm{Y}}=16.892+0.147 \mathrm{NG} / \mathrm{S}$ \\
\hline & 9 & $\mathrm{NG} / \mathrm{S}, \mathrm{NS} / \mathrm{P}$ & 0.544 & $\hat{\mathrm{Y}}=-12.930+0.258 \mathrm{NG} / \mathrm{S}+3.062 \mathrm{NS} / \mathrm{P}$ \\
\hline & 10 & NG/S, NS/P, 100GW & 0.931 & $\begin{array}{l}\hat{Y}=-48.25+0.320 \mathrm{NG} / \mathrm{S}+3.867 \mathrm{NS} / \mathrm{P}+4.578 \\
100 \mathrm{GW}\end{array}$ \\
\hline
\end{tabular}

TABLE 8. Simple, multiple and stepwise analysis in different models for grain yield/plant under drought.

\begin{tabular}{|c|c|c|c|c|}
\hline $\begin{array}{l}\text { Reg. } \\
\text { type }\end{array}$ & $\begin{array}{c}\text { Model } \\
\text { No. }\end{array}$ & Independent trait/s & $\mathbf{R}^{2}$ & Regression equation \\
\hline \multirow{3}{*}{ Simple } & 1 & $\mathrm{NS} / \mathrm{P}$ & 0.693 & $\hat{\mathrm{Y}}=6.136+2.203 \mathrm{NS} / \mathrm{P}$ \\
\hline & 2 & $\mathrm{NG} / \mathrm{S}$ & 0.000 & $\hat{\mathrm{Y}}=18.867+0.003 \mathrm{NG} / \mathrm{S}$ \\
\hline & 3 & $100 \mathrm{GW}$ & 0.043 & $\hat{\mathrm{Y}}=28.059-1.902100 \mathrm{GW}$ \\
\hline \multirow{4}{*}{ Multiple } & 4 & $\mathrm{NS} / \mathrm{P}, \mathrm{NG} / \mathrm{S}$ & 0.836 & $\hat{\mathrm{Y}}=-7.167+2.648 \mathrm{NS} / \mathrm{P}+0.152 \mathrm{NG} / \mathrm{S}$ \\
\hline & 5 & $\mathrm{NS} / \mathrm{P}, 100 \mathrm{GW}$ & 0.707 & $\hat{\mathrm{Y}}=-0.311+2.335 \mathrm{NS} / \mathrm{P}+1.20100 \mathrm{GW}$ \\
\hline & 6 & $\mathrm{NG} / \mathrm{S}, 100 \mathrm{GW}$ & 0.046 & $\hat{\mathrm{Y}}=30.256-0.021 \mathrm{NG} / \mathrm{S}-2.055100 \mathrm{GW}$ \\
\hline & 7 & $\mathrm{NS} / \mathrm{P}, \mathrm{NG} / \mathrm{S}, 100 \mathrm{GW}$ & 0.978 & $\hat{\mathrm{Y}}=-39.204+3.413 \mathrm{NS} / \mathrm{P}+0.246 \mathrm{NG} / \mathrm{S}+4.423100 \mathrm{GW}$ \\
\hline \multirow{3}{*}{ Stepwise } & 8 & $\mathrm{NS} / \mathrm{P}$ & 0.693 & $\hat{\mathrm{Y}}=6.136+2.203 \mathrm{NS} / \mathrm{P}$ \\
\hline & 9 & $\mathrm{NG} / \mathrm{S}, \mathrm{NS} / \mathrm{P}$ & 0.836 & $\hat{\mathrm{Y}}=-7.167+2.648 \mathrm{NS} / \mathrm{P}+0.152 \mathrm{NG} / \mathrm{S}$ \\
\hline & 10 & $\mathrm{NG} / \mathrm{S}, \mathrm{NS} / \mathrm{P}, 100 \mathrm{GW}$ & 0.978 & $\hat{\mathrm{Y}}=-39.204+3.413 \mathrm{NS} / \mathrm{P}+0.246 \mathrm{NG} / \mathrm{S}+4.423100 \mathrm{GW}$ \\
\hline
\end{tabular}


TABLE 9. Realized and expected grain yield/plant from different models of simple, multiple and stepwise regression analysis and their $\mathrm{Chi}^{2}$, correlation $(\mathrm{R})$ and determination $\left(\mathrm{R}^{2}\right)$ coefficients under normal irrigation.

\begin{tabular}{|c|c|c|c|c|c|c|c|c|c|c|c|}
\hline \multirow{3}{*}{ Gen. no } & \multirow{3}{*}{$\begin{array}{c}\text { Realized } \\
\text { GY/P, } \\
\text { gm }\end{array}$} & \multicolumn{10}{|c|}{ Expected GY/P (gm) } \\
\hline & & \multicolumn{3}{|c|}{ Simple regression } & \multicolumn{4}{|c|}{ Multiple regression } & \multicolumn{3}{|c|}{ Stepwise regression } \\
\hline & & $\begin{array}{c}\text { Mod. } \\
1\end{array}$ & $\begin{array}{c}\text { Mod. } \\
2\end{array}$ & $\begin{array}{c}\text { Mod. } \\
3\end{array}$ & $\begin{array}{c}\text { Mod. } \\
4\end{array}$ & $\begin{array}{c}\text { Mod. } \\
5\end{array}$ & $\begin{array}{c}\text { Mod. } \\
6\end{array}$ & $\begin{array}{c}\text { Mod. } \\
7\end{array}$ & $\begin{array}{c}\text { Mod. } \\
8\end{array}$ & $\begin{array}{c}\text { Mod. } \\
9\end{array}$ & $\begin{array}{c}\text { Mod. } \\
10\end{array}$ \\
\hline 1 & 28.81 & 28.32 & 28.51 & 27.33 & 29.04 & 27.53 & 27.56 & 28.17 & 28.51 & 29.04 & 28.17 \\
\hline 13 & 28.93 & 26.91 & 31.75 & 27.13 & 31.72 & 25.60 & 31.10 & 31.24 & 31.75 & 31.72 & 31.24 \\
\hline 39 & 33.34 & 26.94 & 30.32 & 29.38 & 29.30 & 28.21 & 32.10 & 31.95 & 30.32 & 29.30 & 31.95 \\
\hline 42 & 30.79 & 27.09 & 29.21 & 29.57 & 27.67 & 28.62 & 31.04 & 30.23 & 29.21 & 27.67 & 30.23 \\
\hline 48 & 23.50 & 26.47 & 28.10 & 27.74 & 24.45 & 25.76 & 27.57 & 23.07 & 28.10 & 24.45 & 23.07 \\
\hline 62 & 29.01 & 28.71 & 27.97 & 27.75 & 28.92 & 28.49 & 27.43 & 28.73 & 27.97 & 28.92 & 28.73 \\
\hline 63 & 29.81 & 27.80 & 27.34 & 31.28 & 25.90 & 31.44 & 30.89 & 30.87 & 27.34 & 25.90 & 30.87 \\
\hline 68 & 35.53 & 28.38 & 28.89 & 30.26 & 29.83 & 30.98 & 31.48 & 34.11 & 28.89 & 29.83 & 34.11 \\
\hline 74 & 29.45 & 25.96 & 30.35 & 30.39 & 27.30 & 28.20 & 33.35 & 31.15 & 30.35 & 27.30 & 31.15 \\
\hline 92 & 31.16 & 27.09 & 32.27 & 27.19 & 33.00 & 25.88 & 31.78 & 32.95 & 32.27 & 33.00 & 32.95 \\
\hline 95 & 28.18 & 28.03 & 28.94 & 26.97 & 29.17 & 26.77 & 27.63 & 27.73 & 28.94 & 29.17 & 27.73 \\
\hline 104 & 30.96 & 28.06 & 30.97 & 25.94 & 32.79 & 25.63 & 28.78 & 30.57 & 30.97 & 32.79 & 30.57 \\
\hline 124 & 29.80 & 28.60 & 27.24 & 29.26 & 27.41 & 30.08 & 28.36 & 29.35 & 27.24 & 27.41 & 29.35 \\
\hline 129 & 27.36 & 27.85 & 27.77 & 28.20 & 26.78 & 27.97 & 27.73 & 26.78 & 27.77 & 26.78 & 26.78 \\
\hline 139 & 37.85 & 27.87 & 29.51 & 32.00 & 29.83 & 32.35 & 34.28 & 37.05 & 29.51 & 29.83 & 37.05 \\
\hline 145 & 25.33 & 27.10 & 28.52 & 27.28 & 26.50 & 26.00 & 27.50 & 24.88 & 28.52 & 26.50 & 24.88 \\
\hline 150 & 23.92 & 27.42 & 27.88 & 26.58 & 26.05 & 25.58 & 25.92 & 23.13 & 27.88 & 26.05 & 23.13 \\
\hline 151 & 25.48 & 29.58 & 25.40 & 28.69 & 26.29 & 30.62 & 25.54 & 26.97 & 25.40 & 26.29 & 26.97 \\
\hline 170 & 29.26 & 29.56 & 26.42 & 29.16 & 28.00 & 31.14 & 27.29 & 29.93 & 26.42 & 28.00 & 29.93 \\
\hline 202 & 30.54 & 28.16 & 28.36 & 28.65 & 28.46 & 28.86 & 28.95 & 29.66 & 28.36 & 28.46 & 29.66 \\
\hline 206 & 27.91 & 26.96 & 29.54 & 27.64 & 27.98 & 26.24 & 29.13 & 27.35 & 29.54 & 27.98 & 27.35 \\
\hline 209 & 27.78 & 28.23 & 27.92 & 27.74 & 27.82 & 27.89 & 27.35 & 27.32 & 27.92 & 27.82 & 27.32 \\
\hline 245 & 25.86 & 27.86 & 28.41 & 26.85 & 27.91 & 26.43 & 26.87 & 25.94 & 28.41 & 27.91 & 25.94 \\
\hline 246 & 24.94 & 29.21 & 26.61 & 27.02 & 27.59 & 28.26 & 24.96 & 25.81 & 26.61 & 27.59 & 25.81 \\
\hline 296 & 25.04 & 29.73 & 27.47 & 25.28 & 30.19 & 26.89 & 23.89 & 26.16 & 27.47 & 30.19 & 26.16 \\
\hline 300 & 27.72 & 28.73 & 26.91 & 28.28 & 27.12 & 29.13 & 26.83 & 27.35 & 26.91 & 27.12 & 27.35 \\
\hline 306 & 27.88 & 28.05 & 27.37 & 28.70 & 26.51 & 28.79 & 27.86 & 27.28 & 27.37 & 26.51 & 27.28 \\
\hline 343 & 27.21 & 29.04 & 27.09 & 27.61 & 28.08 & 28.72 & 26.23 & 27.42 & 27.09 & 28.08 & 27.42 \\
\hline 352 & 26.96 & 29.22 & 25.72 & 29.96 & 26.08 & 31.66 & 27.44 & 28.87 & 25.72 & 26.08 & 28.87 \\
\hline 378 & 31.95 & 28.90 & 29.06 & 27.35 & 31.23 & 28.26 & 28.22 & 30.96 & 29.06 & 31.23 & 30.96 \\
\hline 379 & 30.07 & 29.89 & 27.78 & 26.90 & 31.07 & 28.95 & 26.20 & 30.01 & 27.78 & 31.07 & 30.01 \\
\hline 389 & 27.22 & 28.08 & 26.76 & 29.69 & 25.50 & 29.95 & 28.32 & 27.67 & 26.76 & 25.50 & 27.67 \\
\hline 395 & 28.31 & 27.80 & 28.60 & 27.67 & 28.13 & 27.30 & 28.07 & 27.58 & 28.60 & 28.13 & 27.58 \\
\hline 397 & 31.21 & 29.57 & 27.67 & 27.99 & 30.19 & 29.81 & 27.36 & 30.74 & 27.67 & 30.19 & 30.74 \\
\hline 423 & 25.53 & 28.59 & 26.38 & 28.55 & 25.90 & 29.27 & 26.53 & 26.27 & 26.38 & 25.90 & 26.27 \\
\hline 459 & 21.41 & 26.26 & 26.67 & 28.44 & 21.53 & 26.32 & 26.73 & 20.56 & 26.67 & 21.53 & 20.56 \\
\hline 463 & 32.06 & 30.13 & 27.48 & 27.52 & 31.05 & 29.95 & 26.57 & 31.02 & 27.48 & 31.05 & 31.02 \\
\hline Sids4 & 18.23 & 24.54 & 28.43 & 27.82 & 20.98 & 23.50 & 28.05 & 18.82 & 28.43 & 20.98 & 18.82 \\
\hline Giza168 & 24.77 & 27.27 & 26.62 & 29.13 & 23.56 & 28.33 & 27.50 & 24.28 & 26.62 & 23.56 & 24.28 \\
\hline $\mathrm{Chi}^{2}$ & & 16.34 & 14.56 & 15.16 & 8.2 & 12.57 & 10.98 & 1.19 & 14.56 & 8.2 & 1.19 \\
\hline $\mathrm{R}$ & & 0.332 & 0.425 & 0.385 & 0.738 & 0.550 & 0.621 & 0.965 & 0.424 & 0.738 & 0.965 \\
\hline $\mathrm{R}^{2}$ & & 0.110 & 0.180 & 0.148 & 0.544 & 0.303 & 0.386 & 0.931 & 0.180 & 0.544 & 0.931 \\
\hline
\end{tabular}


TABLE 10. Realized and expected grain yield/plant from different models of simple, multiple and stepwise regression analysis and their $C_{h i}{ }^{2}$, correlation $(R)$ and determination $\left(\mathbf{R}^{2}\right)$ coefficients under drought.

\begin{tabular}{|c|c|c|c|c|c|c|c|c|c|c|c|}
\hline \multirow{3}{*}{ Gen. no } & \multirow{3}{*}{$\begin{array}{c}\text { Realized } \\
\text { GY/P, gm }\end{array}$} & \multicolumn{10}{|c|}{ Expected GY/P, gm. } \\
\hline & & \multicolumn{3}{|c|}{ Simple regression } & \multicolumn{4}{|c|}{ Multiple regression } & \multicolumn{3}{|c|}{ Stepwise regression } \\
\hline & & $\begin{array}{c}\text { Mod. } \\
1\end{array}$ & $\begin{array}{c}\text { Mod. } \\
2\end{array}$ & $\begin{array}{c}\text { Mod. } \\
3\end{array}$ & $\begin{array}{c}\text { Mod. } \\
4\end{array}$ & $\begin{array}{c}\text { Mod. } \\
5\end{array}$ & $\begin{array}{c}\text { Mod. } \\
6\end{array}$ & $\begin{array}{c}\text { Mod. } \\
7\end{array}$ & $\begin{array}{c}\text { Mod. } \\
8\end{array}$ & $\begin{array}{c}\text { Mod. } \\
9\end{array}$ & $\begin{array}{c}\text { Mod. } \\
10\end{array}$ \\
\hline 1 & 18.66 & 17.43 & 19.07 & 17.93 & 16.84 & 18.04 & 17.88 & 18.35 & 17.43 & 16.84 & 18.35 \\
\hline 13 & 19.24 & 18.58 & 19.08 & 18.98 & 18.83 & 18.61 & 18.92 & 18.65 & 18.58 & 18.83 & 18.65 \\
\hline 39 & 17.77 & 18.01 & 19.08 & 19.23 & 17.92 & 17.85 & 19.23 & 16.83 & 18.01 & 17.92 & 16.83 \\
\hline 42 & 14.44 & 17.34 & 19.04 & 18.37 & 14.85 & 17.67 & 18.61 & 14.15 & 17.34 & 14.85 & 14.15 \\
\hline 48 & 14.17 & 17.00 & 19.06 & 19.52 & 15.72 & 16.60 & 19.67 & 13.03 & 17.00 & 15.72 & 13.03 \\
\hline 62 & 20.72 & 20.81 & 19.05 & 18.52 & 19.89 & 21.26 & 18.65 & 20.46 & 20.81 & 19.89 & 20.46 \\
\hline 63 & 15.97 & 15.03 & 19.09 & 18.10 & 14.83 & 15.40 & 17.94 & 15.73 & 15.03 & 14.83 & 15.73 \\
\hline 68 & 18.99 & 16.55 & 19.11 & 18.70 & 17.68 & 16.63 & 18.45 & 18.28 & 16.55 & 17.68 & 18.28 \\
\hline 74 & 12.85 & 13.29 & 19.12 & 19.05 & 14.21 & 12.95 & 18.76 & 13.27 & 13.29 & 14.21 & 13.27 \\
\hline 92 & 16.02 & 15.22 & 19.16 & 20.43 & 18.53 & 14.13 & 19.98 & 16.21 & 15.22 & 18.53 & 16.21 \\
\hline 95 & 20.44 & 20.61 & 19.06 & 18.99 & 20.19 & 20.75 & 19.09 & 19.95 & 20.61 & 20.19 & 19.95 \\
\hline 104 & 18.95 & 20.73 & 19.07 & 20.05 & 20.87 & 20.21 & 20.15 & 18.54 & 20.73 & 20.87 & 18.54 \\
\hline 124 & 18.50 & 18.43 & 19.06 & 18.44 & 17.55 & 18.78 & 18.50 & 17.89 & 18.43 & 17.55 & 17.89 \\
\hline 129 & 16.28 & 17.09 & 19.07 & 18.66 & 16.05 & 17.23 & 18.72 & 15.52 & 17.09 & 16.05 & 15.52 \\
\hline 139 & 16.29 & 15.08 & 19.11 & 18.58 & 15.93 & 15.14 & 18.32 & 16.36 & 15.08 & 15.93 & 16.36 \\
\hline 145 & 19.96 & 18.66 & 19.09 & 19.15 & 19.32 & 18.58 & 19.05 & 19.00 & 18.66 & 19.32 & 19.00 \\
\hline 150 & 15.83 & 17.45 & 19.07 & 19.26 & 16.74 & 17.23 & 19.33 & 15.09 & 17.45 & 16.74 & 15.09 \\
\hline 151 & 20.36 & 22.07 & 19.04 & 18.88 & 20.86 & 22.37 & 19.12 & 20.65 & 22.07 & 20.86 & 20.65 \\
\hline 170 & 22.17 & 22.93 & 19.05 & 19.23 & 22.53 & 23.06 & 19.40 & 22.19 & 22.93 & 22.53 & 22.19 \\
\hline 202 & 21.58 & 19.76 & 19.08 & 18.73 & 20.02 & 20.01 & 18.68 & 20.64 & 19.76 & 20.02 & 20.64 \\
\hline 206 & 20.69 & 19.07 & 19.10 & 19.25 & 20.06 & 18.95 & 19.12 & 19.81 & 19.07 & 20.06 & 19.81 \\
\hline 209 & 18.46 & 18.67 & 19.09 & 19.50 & 18.97 & 18.37 & 19.48 & 17.63 & 18.67 & 18.97 & 17.63 \\
\hline 245 & 17.32 & 17.91 & 19.09 & 19.63 & 18.21 & 17.49 & 19.60 & 16.42 & 17.91 & 18.21 & 16.42 \\
\hline 246 & 17.38 & 21.68 & 19.04 & 19.86 & 20.19 & 21.34 & 20.20 & 17.47 & 21.68 & 20.19 & 17.47 \\
\hline 296 & 21.87 & 22.63 & 19.10 & 20.53 & 24.25 & 21.92 & 20.53 & 22.07 & 22.63 & 24.25 & 22.07 \\
\hline 300 & 20.42 & 21.24 & 19.06 & 19.07 & 20.71 & 21.37 & 19.20 & 20.35 & 21.24 & 20.71 & 20.35 \\
\hline 306 & 23.99 & 21.17 & 19.07 & 18.30 & 21.42 & 21.78 & 18.27 & 23.29 & 21.17 & 21.42 & 23.29 \\
\hline 343 & 18.67 & 19.54 & 19.06 & 18.67 & 18.52 & 19.82 & 18.80 & 18.44 & 19.54 & 18.52 & 18.44 \\
\hline 352 & 17.45 & 19.51 & 19.06 & 19.30 & 18.54 & 19.38 & 19.47 & 17.03 & 19.51 & 18.54 & 17.03 \\
\hline 378 & 24.91 & 22.15 & 19.09 & 19.13 & 23.33 & 22.29 & 19.05 & 24.05 & 22.15 & 23.33 & 24.05 \\
\hline 379 & 25.30 & 22.39 & 19.12 & 20.18 & 25.06 & 21.89 & 19.99 & 24.31 & 22.39 & 25.06 & 24.31 \\
\hline 389 & 20.13 & 18.47 & 19.07 & 18.10 & 18.08 & 19.04 & 18.06 & 19.52 & 18.47 & 18.08 & 19.52 \\
\hline 395 & 24.02 & 22.44 & 19.09 & 19.82 & 23.87 & 22.17 & 19.77 & 23.20 & 22.44 & 23.87 & 23.20 \\
\hline 397 & 23.32 & 22.89 & 19.08 & 19.47 & 23.55 & 22.86 & 19.52 & 23.29 & 22.89 & 23.55 & 23.29 \\
\hline 423 & 19.29 & 19.97 & 19.06 & 19.15 & 19.41 & 19.98 & 19.25 & 18.61 & 19.97 & 19.41 & 18.61 \\
\hline 459 & 17.51 & 18.97 & 19.06 & 18.98 & 17.98 & 19.02 & 19.11 & 17.11 & 18.97 & 17.98 & 17.11 \\
\hline 463 & 22.45 & 20.58 & 19.08 & 18.99 & 21.21 & 20.72 & 18.94 & 21.61 & 20.58 & 21.21 & 21.61 \\
\hline Sids4 & 14.51 & 13.78 & 19.11 & 18.07 & 14.20 & 14.09 & 17.79 & 15.31 & 13.78 & 14.20 & 15.31 \\
\hline Giza168 & 16.85 & 18.59 & 19.05 & 18.82 & 17.12 & 18.71 & 18.99 & 16.24 & 18.59 & 17.12 & 16.24 \\
\hline $\mathrm{Chi}^{2}$ & & 5.60 & 18.65 & 17.8 & 3.03 & 5.37 & 17.78 & 0.86 & 5.6 & 3.03 & 0.86 \\
\hline $\mathrm{R}$ & & 0.832 & 0.000 & 0.207 & 0.914 & 0.841 & 0.214 & 0.989 & 0.832 & 0.914 & 0.989 \\
\hline $\mathrm{R}^{2}$ & & 0.693 & 0.000 & 0.043 & 0.836 & 0.707 & 0.046 & 0.978 & 0.693 & 0.836 & 0.978 \\
\hline
\end{tabular}




\section{Conclusion}

Grain yield was positively correlated with each of a number of spikes/plant and number of grains/spike under the two conditions. Path analysis revealed positive direct effects on grain yield/plant via a number of grains/spike under irrigation and number of spikes/plant under drought. The direct effect of 100 -grain weight on grain yield/plant was positive under the two environments. The indirect effects of these traits were negative under the two conditions. Stepwise regression analysis revealed that model no. 10 was fitted for each environment and superior to use in selection for grain yield/plant.

\section{$\underline{\text { References }}$}

Abd El-Mohsen, A.A. and Abd El-Shafi, M.A. (2014) Regression and path analysis in Egyptian bread wheat. J. Agri-Food and Applied Sci. 2(5), 139148.

Bhutto, A.H., Rajpar, A.A., Kalhoro, S.A., Ali, A., Kalhoro, F.A., Ahmed, M., Raza, S. and Kalhoro, N.A. (2016) Correlation and regression analysis for yield traits in wheat (Triticum aestivum L) genotypes. Natural Sci. 8, 96-104.

Çifci, E.A. (2012) Estimate of heterosis, correlation and path analysis for grain yield per spike and some agronomic traits on durum wheat (Triticum durum Desf). The J Animal \& Plant Sci. 22(3), 747-752.

Desheva, G. (2016) Correlation and path-coefficient analysis of quantitative characters in winter bread wheat varieties. Trakia J. Sci. 1, 24-29.

Dewey, D.R. and Lu, K.H. (1959) A correlation and path coefficient analysis of components of crested wheat grass seed production. Agron. J. 51, 515-518.

Dixet, P. and Dubey, D.K. (1984) Path analysis in lentil (Lens culinaris Medic.). Lens Newsletter, 11, 1517.

El-Rawi, K. and Khalafala, A.M. (1980) "Design and Analysis of Agricultural Experiments". El-Mousel Univ. Iraq, pp.79-80.

Guler, M., Adak, M.S. and Ulukan, H. (2001) Determining relationships among yield and some yield components using path coefficient analysis in chickpea (Cicer arietinum L). Europ. J. Agronomy, 14, 161-166.
Jan, N., Lal, E.P., Kashyap, S.C. and Parr, G.A. (2017) Character association and path analysis in wheat (Triticum aestivum $\mathrm{L}$ em thell) under temperate conditions of Kashmir, India. Plant Archives, 17 (1), 43-50.

Janmohammadi, M., Sabaghnia, N. and Nouraein, M. (2014) Path analysis of grain yield and yield components and some agronomic traits in bread wheat. Acta Univ Agric et Silviculturae Mendelianae Brunensis. 62(5), 945-952.

Johnson, W.H., Robinson, H.F. and Comstock, R.E. (1955) Estimates of genetic and environmental variability in soybeans. Agron. Jour. 47(7), 314319.

Khames, K. M., Abo-Elwafa, A., Mahmud, A.M. and Hamada, A. (2016) Correlation, path-coefficient, normal and stepwise regression analyses via two cycles of pedigree selection in bread wheat (Triticum aestivum L). Assiut J. Agric. Sci. 47(4), 84-108.

Khan, A.A., Alam, M.A., Alam, M.K., Alam, M.J. and Sarker, Z.I. (2013) Correlation and path analysis of durum wheat (Triticum turgidum L var. Durum). Bangladesh J. Agric. Res. 38(3), 515-521.

Khan, A.J., Azam, F., Ali, A., Tariq, M. and Amin, M. (2005) Inter-relationship and path coefficient analysis for biometric traits in drought tolerant wheat (Triticum aestivum L). Asian J. Plant Sci. 4 (5), 540-543.

Khan, N. and Naqvi, F.N. (2012) Correlation and path coefficient analysis in wheat genotypes under irrigated and non-irrigated conditions. Asian J. Agric. Sci. 4(5), 346-351.

Khokhar, M.I., Hussain, M., Zulkiffal, M., Ahmad, N. and Sabar, W. (2010) Correlation and path analysis for yield and yield contributing characters in wheat (Triticum aestivum L). African J. Plant Sci. 4(11), 464-466.

Mahdy, E.E., El-Karamity, A.E., Mokadem, S.A. and Fouad, H.M. (2015) Selection for earliness in bread wheat under normal irrigation and drought stress conditions. J. Plant Production, Mansoura Univ. 6(4), 529-545.

Mohamed, N.A. (1999) Some statistical procedures for evaluation of the relative contribution for yield 
components in wheat. Zagazig J. Agric. Res. 26(2), 281-290

Nasri, R., Kashani, A., Paknejad, F., Vazan, S. and Barary, M. (2014) Correlation, path analysis and stepwise regression in yield and yield components in wheat (Triticum aestivum $\mathrm{L}$ ) under the temperate climate of Ilam province, Iran. Indian J. of Fundamental and Applied Life Sci. 4(4),188-198.

Rasheed, B., Rasheed, H.U., Khan, A. and Farid, A. (2015) Association and path analysis of exotic wheat genotypes for yield and yield components. $J$. Agric. Sci. Res. 2(2), 21-28.

Singh, G. and Chaudhary, H. (2006) Selection parameters and yield enhancement of wheat (Triticum aestivum L) under different moisture stress condition. Asian J. Plant Sci. 5, 894-898.
Soleymanifard, A., Naseri, R. and Meysam, M. (2012) The study genetic variation and factor analysis for agronomic traits of Durum wheat genotypes using cluster analysis and path analysis under drought stress condition in western of Iran. Inter. Res. J. Applied and Basic Sci. 3(3), 479- 485.

Steel, R.G.D. and Torrie, J.H. (1980) "Principle and Procedures of Statistics. A Biometrical Approach" $2^{\text {nd }}$ ed., McGraw-Hill Book Company, New York. U.S. A. 633 pages.

Zecevic, V., Knezevic, D. and Micanovic, D. (2004) Genetic correlation and path-coefficient analysis of yield and quality components in wheat (Triticum aestivum L) Genetika, 36(1), 13-21.

(Received 6/ $3 / 2017$ accepted $5 / 7 / 2018$

\section{تحليل الأرتباط والمرور والإتحدار في بعض التراكيب الوراثية من قمح الخبز تحت ظروف

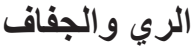 قسم المحاصيل ـ كلية الزفر اعة ـ جامعة المنيا ـ المنيا ـ مصر.}

الهدف من هذه الدر اسة هو تقدير تحليل الإرنباط والمرور و الإنحدار فى 39 تركيب ور اثى من قمح الخبز خلال

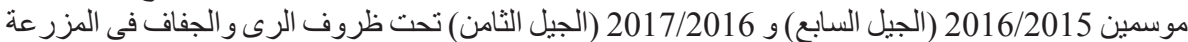

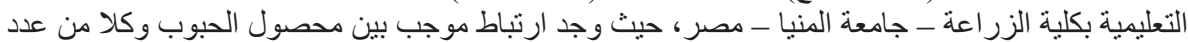

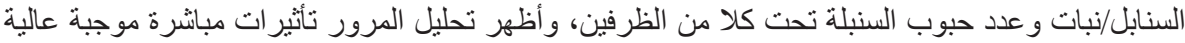

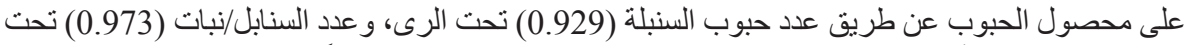

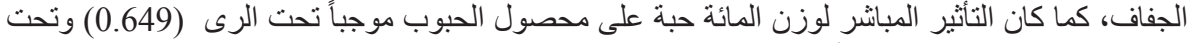

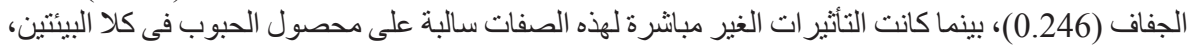

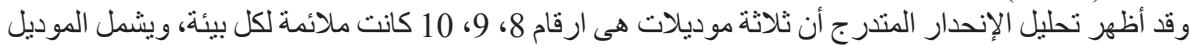

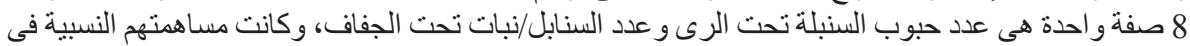

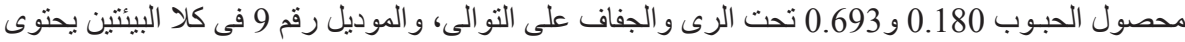

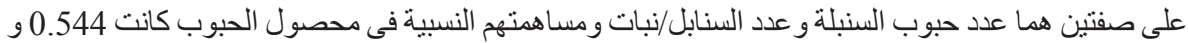

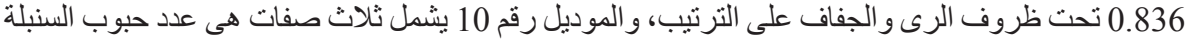

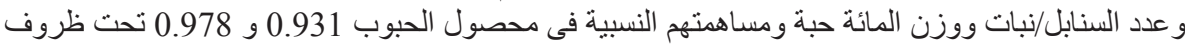
الرى و الجفاف على التو الى ، ويعتبر هذا الموديل 8 مناسب و اكثر ملائمة للانتخاب لمحصول الحبوب لكل نبل نبات. 